Child abuse among working children in rural Bangladesh: prevalence and determinants

Abdullahel Hadi

Research and Evaluation Division BRAC Centre

75 Mohakhali

Dhaka 1212, Bangladesh 


\section{Abstract \\ Child abuse among working children in rural Bangladesh: prevalence and determinants}

The paper aims to improve our understanding about the prevalence and determinants of child abuse in rural Bangladesh. Data from the 1995 sample survey of 4,643 children aged 10-15 years in 150 villages were used. Findings revealed that $21 \%$ of the children were in the labour force although the Bangladeshi laws prohibited child labour. The prevalence of child abuse and exploitation was widespread in Bangladeshi villages as $2.3 \%$ of all children were physically abused, $2 \%$ were financially exploited, $1.7 \%$ were forced to involve in inappropriate activities, and $3 \%$ were forced to work for long hours. The prevalence of physical assault was much higher among younger children although the probability of other types of abuse was higher among older children. Boys were more exposed than girls to be abused of any kind. Poverty was also significantly associated with child abuse. Multivariate analysis suggested that the out-of-school children and the children of illiterate, landless and unskilled labourers were more likely to be abused than others when age and sex of children were controlled. The paper concludes that raising public awareness against child abuse and promoting preventive measures should be adopted to reduce child abuse in Bangladesh.

Keywords: Child abuse; child labour; poverty; schooling; network 


\section{Introduction}

Despite significant progress in the global situation of children during the last couple of decades, many children still suffer from poverty, homelessness and lack of access to education systems. ${ }^{1}$ Millions of children are working in abysmal conditions in farms and factories. International Labour Organisation (ILO) estimated that at least $15 \%$ of all 10-14 years old children in Asia were in the labour force in 1996. ${ }^{2}$ Most of them work for long hours on farms and industries in dangerous work environment.

It is not known exactly what proportion of children are in the workforce in Bangladesh. According to the 1983-84 Labour Force Survey, ${ }^{3}$ the proportion of child labour in 10-14 age group was nearly $25 \%$ which increased to $34.4 \%$ in 1989 . A recent estimate indicated that $20 \%$ of the boys were working in 1996 compared to only $4 \%$ among girls. ${ }^{4}$ The proportion of children in the labour force in Bangladesh has consistently been increasing and likely to increase even further as a result of pervasive poverty in the rural areas. The general impression about child labour situation in Bangladesh is that children work for long hours, low wages, and in hazardous conditions. Elimination of child labour is a desirable social goal, but the poverty factors pose a serious obstacle in achieving it.

The economic condition of the majority families in rural Bangladesh are of subsistence type based primarily on agricultural activities. The children in the labour force were employed in such types of activities as livestock raising, paddy husking, small trading, cooking, housekeeping, etc. Such a labour intensive mode of employment continued for generations in villages. Involvement of children in the workforce has not been considered wrong as it not only adds to their family income but also helps prepare themselves for the future. ${ }^{4}$ Many accept it as a means of acquiring the necessary skills that develops the confidence and self respect, and prepare them to take over the responsibilities from elders. ${ }^{5}$ However, most often the child labour implies that children are doing things that are harmful to their physical and mental development. ${ }^{4}$ The child labour may impair healthy mental development in many ways as it exposes children to the risks of physical, psychological or sexual abuse. As immature workers, they are particularly vulnerable to abuse if they fail to perform their duties satisfactorily. Exposure to unhygienic working environment such as heat, dust and smoke can also cause damage to their health and well-being. ${ }^{4}$

Although the UN Convention on the Rights of the Children declares that child's best interest should always be the prime consideration in determining all actions affecting children, ${ }^{6}$ child abuse among working children has remained as a global problem. ${ }^{7-10}$ While the reduction of child abuse has becoming an important issue in the development discourse in many countries, very little is known about the prevalence and determinants of child abuse. ${ }^{9}$ 
A review of existing research suggests that information gap regarding child abuse among working children needs to be addressed to identify intervention points. In developing societies, child abuse is less likely to be recognised as a major social or public health problem. Thus, the documentation of the prevalence of abuse is expected to be poor. In Bangladesh, very few organisations have shown interest in this issue of reducing child abuse and neglect. Human right groups and a few nongovernmental development organisations have initiated programmes to raise awareness of the efficacy of child abuse with limited success. As found elsewhere, child abuse is more likely to occur in workplace than in family context. ${ }^{11-12}$ This paper estimates the proportion of children (10-15 years) in the workforce and aims to improve our understanding about the prevalence and determinants of child abuse in rural Bangladesh.

\section{Methods}

Study design

Data used in this study came from an open-ended survey, launched in March 1995 in 150 villages located in four sub-districts of Bangladesh where BRAC has a demographic surveillance system since mid 1980s. Some of the villages were located near the urban centres in the sub-districts. Thus, a significant proportion of the study children had opportunity to be involved as transport workers, factory helpers, housekeepers and domestic servants. A list of all children aged between 10-15 years in the study villages consisted the sampling frame for the survey. Systematic random sampling technique was followed where one in every fifth household was selected. All sample children were interviewed that provided a typical description of the whole day activity, time spent for each child and the living condition in addition to the basic demographic and socio-economic characteristics. In many cases, maintaining privacy during interviews was difficult that led to incomplete interviews. Nearly $90 \%(4,643)$ of the children were successfully interviewed. The structured interviews focused on the demographic and socio-economic characteristics of the children while the child abuse issues were captured by open-ended interviews.

\section{Definition of variables}

The meaning of child labour and child abuse varies considerably. Children (5-15 years) who were found employed during the reference period was considered child labour by the Bangladesh Bureau of Statistics (BBS) ${ }^{13}$ Amount of time spent was focused in one study and considered that a minimum of seven 
working hours a week would be required to be termed as child labour. ${ }^{14}$ In the present study, all working children aged 10-15 years engaged in economic activity for at least four hours a day regardless of employment status and remuneration were considered as working children.

The study focused on child abuse. Any act of physical aggression, economic exploitation, neglect related to health and well-being, and mental torture was termed as child abuse in this study. As no universally accepted indicators of child abuse was found, we focused on a limited forms of child abuse among working children. These were: a) physical assault or beating; b) financial exploitation or not paying full wages; c) forced to involve in such kind of acts that were not appropriate for children; and d) overburden or too much work to complete in specified time. The explanatory variables or the determinants of child abuse were age and sex of child, school enrollment status, education and occupation of father and amount of land owned by the family.

\section{Analytical procedure}

The analysis begins with a description of the background variables of the sample children by the duration of work. Secondly, the child abuse indicators are differentiated by demographic and poverty-related risk factors. And finally, the net impact of the risk factors on child abuse is examined by employing multivariate analysis. Log odds ratios of explanatory variables in the models are estimated to predict the risk of abuse among sample children. This has helped understand the percentage change in the odds associated with each unit change in the explanatory variables.

In the absence of longitudinal data, this study has followed the cross-sectional approach that might have generated biased estimates. To minimise the possibility of bias, multivariate analysis has been used to control the effects of confounding factors. It should be recognised that the evidence of child abuse and its correlates, estimated in this paper, were more indicative than definitive. The approach followed in this study was not appropriate to draw definite conclusions regarding the role of socio-demographic factors on child abuse. 
Table 1 Proportion of children (10-15 years) in the labour force by socio-economic characteristics and duration of working hours

\begin{tabular}{|c|c|c|c|}
\hline \multirow{2}{*}{$\begin{array}{l}\text { Socio-economic } \\
\text { characteristics }\end{array}$} & \multicolumn{3}{|c|}{ Duration of working hours } \\
\hline & Four + & Six + & Eight + \\
\hline All & 20.8 & 8.0 & 3.1 \\
\hline \multicolumn{4}{|l|}{ Age of child } \\
\hline $10-11$ & 10.5 & 2.1 & 0.4 \\
\hline $12-13$ & 19.8 & 6.9 & 2.7 \\
\hline $14-15 y$ & 32.8 & 15.3 & 6.4 \\
\hline \multicolumn{4}{|l|}{ Sex of child } \\
\hline Boy & 20.0 & 9.1 & 4.1 \\
\hline Girl & 21.8 & 6.7 & 2.1 \\
\hline \multicolumn{4}{|c|}{ Father's education } \\
\hline None & 24.7 & 10.1 & 4.2 \\
\hline $1-5$ & 19.4 & 6.9 & 2.7 \\
\hline $6+$ & 11.0 & 3.0 & 0.6 \\
\hline \multicolumn{4}{|c|}{ Father's occupation } \\
\hline Labourer & 26.2 & 11.4 & 4.9 \\
\hline Others & 18.0 & 6.2 & 2.2 \\
\hline \multicolumn{4}{|l|}{ Amount of land } \\
\hline Landless & 26.4 & 11.2 & 4.9 \\
\hline $1-199 d$ & 19.1 & 6.7 & 2.4 \\
\hline $200+d$ & 12.2 & 3.7 & 0.9 \\
\hline \multicolumn{4}{|l|}{ Father } \\
\hline Alive & 20.0 & 7.5 & 2.9 \\
\hline Dead & 32.7 & 15.0 & 6.3 \\
\hline \multicolumn{4}{|l|}{ School } \\
\hline Enrolled & 14.2 & 3.6 & 0.9 \\
\hline Not enrolled & 46.6 & 24.9 & 11.9 \\
\hline
\end{tabular}

\section{Results}

\section{Profile of working children}

The proportion of children at work by duration of working hour shows that about $20.8 \%$ of the children were in the labour force if working period is considered at least four hours a day (Table 1). Relatively 
few children worked for long hours. While $8.0 \%$ of the children spent at least 6 hours a day, the proportion of children reduced to only $3.1 \%$ who were fully ( $8+$ hours) involved in the labour force. When the duration of working hours was differentiated by demographic and socio-economic characteristics of the study children, work hours spent appeared to have significant positive association with age of children. Although the proportion of children in labour force was high (20.8\%), relatively a smaller proportion of young children was in work force. Data indicate that the entry to work force had a positive and linear association with age of children. More boys than girls were in the workforce in the study areas although the sex difference was not statistically significant among children who worked for long (4+) hours.

The poverty factors had a clear and significant positive association $(\mathrm{p}<0.01)$ with child labour. The poorer and illiterate families, having little or no agricultural land, might be forced to send their children to work for wages. ${ }^{15}$ On the other hand, education of father played a key role in reducing child labour regardless of the working hours of children. Similarly, the probability of a child to be in the labour force was much higher if the father himself was a labourer. As expected, the children of landless families were more likely to be in the labour market than others.

The society expects that the extended kin should support an orphan. But the pressure of poverty often leads to break down this social norm. Data indicate that the death of father forced young children to be in the labour market. The participation in workforce had a significant negative $(p<0.01)$ association with schooling of children. ${ }^{16}$ The reasons of such an association could be many. Time use in work-place might be more demanding than attending school or parents might not be financially capable of keeping their children in school. ${ }^{17}$

\section{Child abuse: prevalence and socio-economic correlates}

Only few studies have focused on the social and economic factors that contribute to child abuse. ${ }^{18}$ Children of the poor families were often drafted to work for their own family or others. Not all children were fortunate to work in pleasant atmosphere particularly who worked for others. The proportion of children exposed to various types of abuse and the potential risk factors regardless of their involvement in the workforce are presented Table 2. Of all study children, about $2.3 \%$ of children reported to be physically assaulted at work while $2 \%$ never received full wages. About $1.7 \%$ of the children were forced to involve in inappropriate acts and $3 \%$ were forced to work for long hours and beyond their physical capacity. 
Table 2 Proportion of children exposed to various types of child abuse by socio-economic factors

\begin{tabular}{|c|c|c|c|c|}
\hline \multirow{2}{*}{$\begin{array}{l}\text { Socio-economic } \\
\text { factors }\end{array}$} & \multicolumn{4}{|c|}{ Type of abuse* } \\
\hline & $\begin{array}{l}\text { Physical } \\
\text { assault }\end{array}$ & $\begin{array}{l}\text { Financial } \\
\text { exploitation }\end{array}$ & $\begin{array}{l}\text { Forced } \\
\text { work }\end{array}$ & $\begin{array}{l}\text { Over } \\
\text { burden }\end{array}$ \\
\hline All & 2.3 & 2.0 & 1.7 & 3.0 \\
\hline \multicolumn{5}{|l|}{ Age of child } \\
\hline $10-11$ & 3.1 & 0.6 & 0.5 & 1.3 \\
\hline $12-13$ & 2.6 & 2.1 & 2.1 & 3.0 \\
\hline $14-15 y$ & 1.3 & 3.5 & 2.6 & 4.8 \\
\hline$P$-value & $<.01$ & $<.01$ & $<.01$ & $<.01$ \\
\hline \multicolumn{5}{|l|}{ Sex of child } \\
\hline Boy & 2.4 & 3.1 & 2.3 & 4.2 \\
\hline Girl & 2.2 & 0.9 & 1.1 & 1.6 \\
\hline$P$-value & $n s$ & $<.01$ & $<.01$ & $<.01$ \\
\hline \multicolumn{5}{|c|}{ Father's education } \\
\hline None & 2.8 & 2.9 & 2.3 & 4.1 \\
\hline $1-5$ & 2.2 & 1.2 & 1.0 & 2.0 \\
\hline $6 \mathrm{y}$ and more & 1.1 & 0.4 & 0.7 & 0.7 \\
\hline$P$-value & $<.05$ & $<.01$ & $<.01$ & $<.01$ \\
\hline \multicolumn{5}{|c|}{ Father's occupation } \\
\hline Labourer & 2.2 & 4.0 & 2.8 & 5.3 \\
\hline Others & 2.4 & 1.0 & 1.2 & 1.8 \\
\hline$P$-value & $n s$ & $<.01$ & $<.01$ & $<.01$ \\
\hline \multicolumn{5}{|l|}{ Land ownership } \\
\hline Landless & 3.2 & 3.1 & 2.7 & 4.8 \\
\hline $1-199 d$ & 1.9 & 1.7 & 1.2 & 2.4 \\
\hline $200+d$ & 1.5 & 0.6 & 0.6 & 0.4 \\
\hline$P$-value & $<.01$ & $<.01$ & $<.01$ & $<.01$ \\
\hline \multicolumn{5}{|l|}{ School } \\
\hline Enrolled & 2.1 & 0.5 & 0.9 & 1.2 \\
\hline Not enrolled & 3.1 & 7.9 & 4.8 & 9.9 \\
\hline$P$-value & $n s$ & $<.01$ & $<.01$ & $<.01$ \\
\hline
\end{tabular}

\footnotetext{
* Any event of beating or slapping in the last one month preceding the interview date was considered as physical abuse. Financial exploitation was regarded as abuse where the child had not given full wages in the last three months. When a child had to work against his/her will or involve in activities not appropriate for them in the last one month was considered forced work. Over burden was aiso considered a form of abuse if a child had to work long hours and beyond his/her physical capacity. ns=not significant.
} 
The prevalence of abuse appeared to be positively associated with the age of children for all categories except physical assault indicating that younger children were more vulnerable than the older ones to be physically abused. Boys were generally more abused than girls in all forms of abuse. The relationship between the prevalence of abuse and the poverty indicators such as education, land ownership and occupation of father clearly indicated who would be at the risk of abuse. It appeared that child abuse had significant negative association with both the fathers' years of schooling and amount of land $(\mathrm{p}<0.01)$. The probability of a child to be abused was higher if his or her father was also a labourer than otherwise. Out-of-school children were also more exposed to be abused than school-goers as the former spent more time in work than later who were enrolled in school.

\section{Factors predicting child abuse: multivariate analysis}

The relative influence of the socio-demographic risk factors to predict various types of child abuse is estimated by logistic regression analysis (Table 3). As found earlier, the incidence of physical assault had reduced while all other types of abuse such as financial exploitation and forced work rose with the age of children. Boys were significantly more likely to be abused than girls. Poverty factors such as literacy, occupation of father and land ownership were also associated negatively with the incidence of child abuse when other variables were controlled. This result confirms our earlier assumption that parental socio-economic condition was significant predictor of child abuse in rural community in Bangladesh. The probability of a child to be abused was lower among children who were in school probably because a significant proportion of their time was spent in the school - a place where the chance to be abused was minimum. Overall, the multivariate analysis clearly shows that the probability of working child to be abused was dependent not only on the age and sex of the child but also the socioeconomic position of their parents. 
Table 3 Log odds ratios of selected explanatory variables to predict various types of child abuse

\begin{tabular}{|c|c|c|c|c|}
\hline \multirow{2}{*}{$\begin{array}{l}\text { Socio-economic } \\
\text { risk factors }\end{array}$} & \multicolumn{4}{|c|}{ Type of abuse } \\
\hline & $\begin{array}{l}\text { Physical } \\
\text { assault }\end{array}$ & $\begin{array}{l}\text { Financial } \\
\text { exploitation }\end{array}$ & $\begin{array}{l}\text { Forced } \\
\text { work }\end{array}$ & $\begin{array}{l}\text { Over } \\
\text { burden }\end{array}$ \\
\hline
\end{tabular}

$\begin{array}{lllll}\text { Age of child } & & & & \\ 10-11 & 1.00 & 1.00 & 1.00 & 1.00 \\ 12-13 & 0.79 & 2.56^{* *} & 3.84^{* * *} & 2.04^{* *} \\ 14-15 \mathrm{y} & 0.34^{* * *} & 2.84^{* * *} & 3.81^{* * *} & 2.33^{* * *}\end{array}$

Sex of child

$\begin{array}{lllll}\text { Boy } & 1.09 & 3.62^{* * *} & 2.22^{* * *} & 2.71^{* * *} \\ \text { Girl } & 1.00 & 1.00 & 1.00 & 1.00\end{array}$

Father's education

$\begin{array}{lllll}\text { None } & 2.39^{* * *} & 2.36 & 1.63 & 2.16^{*} \\ 1-5 & 1.88 & 1.44 & 0.90 & 1.57 \\ 6 y \text { and more } & 1.00 & 1.00 & 1.00 & 1.00\end{array}$

Father's occupation

$\begin{array}{lllll}\text { Labourer } & 0.56^{* *} & 2.31^{* * *} & 1.29 & 1.55^{* *} \\ \text { Others } & 1.00 & 1.00 & 1.00 & 1.00\end{array}$

Land ownership

\begin{tabular}{lllll} 
Landless & $1.92^{*}$ & 1.36 & $2.56^{*}$ & $5.83^{* * *}$ \\
$1-199 \mathrm{~d}$ & 1.15 & 1.28 & 1.51 & $4.21^{* * *}$ \\
$200+\mathrm{d}$ & 1.00 & 1.00 & 1.00 & 1.00 \\
School & & & & \\
$\quad$ Enrolled & 1.00 & 1.00 & 1.00 & 1.00 \\
Not enrolled & $1.74^{* *}$ & $10.1^{* * *}$ & $3.36^{* * *}$ & $5.91^{* * *}$ \\
Constant & $-4.43^{* * *}$ & $-8.03^{* * *}$ & $-.7 .14^{* * *}$ & $-7.82^{* * *}$ \\
\hline Model chi-square & 40.2 & 219.4 & 97.1 & 233.0 \\
$P$-value & 0.00 & 0.00 & 0.00 & 0.00 \\
\hline
\end{tabular}

*** Significant at $P<0.01$.

** Significant at $P<0.05$.

* Significant at $P<0.10$.

\section{Discussion and Conclusion}

Although child abuse has been prevailing in Bangladesh from the historic period, the problem has received serious attention only since the celebration of the International Year of the Child in 1979. The

$$
172
$$


results of this study disclosed an unexplored and sensitive issue that a significant proportion of children might have been suffering considerable damage to their health and well-being. This finding has important policy implications for both the government and non-government agencies in Bangladesh. The study particularly focused on the working children only rather than all children. The reason has been that they were doubly disadvantaged of being the child labourer and abused while struggling for their survival.

The prevalence of child abuse among working children is reasonably high in rural Bangladesh. It is still unclear why older and boys suffered more than others. One explanation is that they were exposed to more hazardous work than younger and girls. It was not expected that all working children would be able to satisfy their employers. But the tendency among the employers in behaving with working children reiterated the assumption that the risk to be abused would remain higher among the poor than other children. Results indicate that the probability of a child to be abused would increase if his/her father was illiterate, landless and labourer. The study has demonstrated a clear linkage between child abuse situation and the pervasive manifestation of poverty. Given the economic and cultural context of Bangladesh, it will be very difficult to improve the child abuse situation in foreseeable future. While the prevalence of abuse among the children enrolled in school was significantly low, it can be suggested that a targeted 'back to school' programme may be an effective response to minimise the sufferings of children at work.

The children in Bangladesh have not only been suffering from poverty, health hazards, and poor access to education, but the child abuse, as additional burden to a significant proportion of children, may impair the socio-emotional and cognitive development processes particularly in their intellectual and linguistic competence. ${ }^{19}$ The task of projecting child abuse as a serious social and health problem would be very difficult in Bangladesh because abuse in the limited scale is considered as part of the socialisation process. The existing cultural values and legal systems do not prohibit child abuse unless the damage it causes to health becomes significantly visible.

While a number of agencies and organisations in Bangladesh have been playing advocacy role to ensure child rights, it is clear that advocacy alone cannot do much to have a significant impact in reducing child abuse in Bangladesh. Child abuse should not only be regarded as a social problem that could be eliminated by raising awareness but that it should also be considered as a serious public health problem. A network of concerned organisations or agencies should work together against the problem of child abuse. ${ }^{20}$ The proposed network should oppose not only all forms of child abuse but also adopt a multi-dimensional approach to prevent and control such abuses. ${ }^{21}$ The primary tasks of the programme should be to raise awareness among public, disseminate information to health providers to undertake 
specific measures to prevent it. As a long-term policy options, the programme should consider establishing legal support network, expansion of non-formal school system ${ }^{22}$ and targeted anti-poverty programme to effectively reduce child abuse problem in Bangladesh.

\section{Acknowledgements}

This research was supported by the Strengthening Research and Evaluation Activities in BRAC Project of the Ford Foundation, Dhaka, Bangladesh. The author is grateful to the funding agency and the children who provided sensitive and valuable information for this research. The author wishes to thank Mr. Hasan Shareef Ahmed of BRAC and an anonymous referee for their constructive criticisms and comments of the earlier version of the paper. 


\section{References}

1 Julianto I. Child Abuse, Street Children and HIV/AIDS - Review on the Rights and Health of the Children. Paper presented at the conference on the fourth Asia-Pacific social science and medicine. Yogyakarta, 1998

2 Far Eastern Economic Review. Child Labour: It Isn't Black and White. Cover Story. Far Eastern Economic Review March 7, 1996.

3 UNICEF. An Analysis of the Situation of Children in Bangladesh. UNICEF, Dhaka, 1987.

4 Stalker P. Child Labour in Bangladesh. A Summary of Recent Investigations. Discussion paper for Interagency Consultation on Child Labour Situation Studies, UNICEF, Dhaka, August, 1996.

5 Kanbargi K. Introduction and Overview. In: Kanbargi $\mathrm{R}$ (ed). Child Labour in the Indian Subcontinent. Dimensions and Implications. Sage Publications, New Delhi, 1991.

6 Moorehead C. All the World's Children. Index on Censorship 1997; 2: 151-160.

7 Segal UA, Ashtekar, A. Detection of Intrafamilial Child Abuse: Children at Intake at a Children's Observation Home in India. Child Abuse and Neglect 1994; 18(11): 957-967.

8 Ebigbo PO. Child Abuse and Neglect in Nigeria - A Situation Analysis. Nigeria's Population 1993; Oct-Dec: $10-14$.

9 D'Antonio IJ, Darwish AM, McLean M. Child Maltreatment: International Perspectives. MaternalChild Nursing Journal 1993; 21(2): 39-52.

10 Milbourn P. Child Abuse: A Collaborative Study in Jamaica. Children in Focus 1992; 4(4): 9-10.

11 Di Blasio P, Camisasca E. Child Abuse: An Analysis of a Global Problem. International Child Health 1996; 7(3): 59-66.

12 Burra N. Violence against Child Labourers: A Slide Presentation. In: Karlekar M, Agarwal A, Ganjoo M (eds). No Safe Spaces. Report of a Workshop on Violence against Women, March 27-28, 1995. Centre for Women's Development Studies, New Delhi, 1995.

13 BBS. Report on Labour Force Survey 1989. Bangladesh Bureau of Statistics, Dhaka, 1992.

14 Khuda B. Division of Labour in Rural Bangladesh. Bangladesh Development Studies 1980; 8(4): 107-120.

15 Vemuri MD, Sastry, UVKV. Participation of in child Labour in the Indian Subcontinent. Dimensions and Implications. In: Kanbargi $\mathrm{R}$ (ed). Child Labour in the Indian Subcontinent. Dimensions and Implications. Sage Publications, New Delhi, 1991. 
16 Kanbargi K, Kulkarni PM. Child Work, Schooling and Fertility in Rural Karnataka, India. In: Kanbargi R (ed). Child Labour in the Indian Subcontinent. Dimensions and Implications. Sage Publications, New Delhi, 1991.

17 Srikantan KS, Narayan BK, Rao DV. Female and Child Work Participation in the Integrated Development of a Command Area. Institute for Social and Economic Change, Bangalore, 1978.

18 Pettigrew J. Child Neglect in Rural Panjabi Families. Journal of Comparative Family Studies 1986; 17(1): 63-85.

19 Kornblit AL. Domestic Violence - An Emergency Health Issue. Social Science \& Medicine 1994; 39(9): 1181-1188.

20 Khan NZ, Lynch MA. Recognising Child Maltreatment in Bangladesh. Child Abuse and Neglect 1997; 21(8): 815-818.

21 Forjuoh SN, Zwi $\mathrm{AB}$. Violence against Children and Adolescents. International perspectives. Pediatric Clinics of North America 1998; 45(2): 415-426.

22 Ramphele MA. Adolescents and Violence: "Adults are Cruel, they Just Beat, Beat, Beat"! Social Science \& Medicine 1997; 45(8): 1189-1197. 